\title{
Effects of Inclusion of Polyunsaturated Fatty Acids and Antioxidants on Spermatozoa Morphology of Potchefstroom Koekoek Cockerels
}

\author{
Caiphus Hlungwani ${ }^{1}$, Francois K. Siebrits ${ }^{1}$, Tshimangadzo L. Nedambale ${ }^{1,2}$ \\ ${ }^{1}$ Tshwane University of Technology, Faculty of Science, Department of Animal Sciences, Pretoria, Republic of \\ South Africa \\ ${ }^{2}$ Agricultural Research Council, Animal Production Institute, Germplasm Conservation and Reproductive \\ Biotechnologies, Irene, Republic of South Africa \\ Email: SiebritsFK@gmail.com
}

Received 14 February 2015; accepted 30 March 2015; published 3 April 2015

Copyright (C) 2015 by authors and Scientific Research Publishing Inc.

This work is licensed under the Creative Commons Attribution International License (CC BY).

http://creativecommons.org/licenses/by/4.0/

(c) (i) Open Access

\begin{abstract}
This study was conducted to determine the effects of increasing dietary polyunsaturated fatty acids (PUFA) and antioxidants (Se and vitamin E) on spermatozoa morphology. At 24 weeks of age, Potchefstroom Koekoek cockerels $(n=60)$ were selected from the base population. Cockerels were randomly allocated into five dietary treatments with 12 cockerels per dietary treatment. The diets consisted of commercial layer diet (CL), commercial cockerel diet (CC), modified layer diet (ML), modified layer diet +PUFA (MLP), and modified layer +PUFA+ antioxidants (MLPA) diet. At 36 weeks of age, six cockerels with $\geq 75 \%$ sperm motility rate following analysis by Computer Aided Sperm Analysis (CASA) were selected from the base population in each dietary treatment group. Semen volume, sperm cells concentration and dead cells did not differ significantly among any of the groups. However, live and normal spermatozoa were significantly higher in the MLPA group. The bent mid-piece, bent mid-piece plus droplets, proximal droplets and distal droplets were significantly lower in the MLPA group. From this study it can be concluded that supplementation of polyunsaturated fatty acids and antioxidants may be of vital importance for normal morphology characteristics of spermatozoa in Potchefstroom Koekoek cockerels.
\end{abstract}

\section{Keywords}

Selenium, Chicken, CASA, Vitamin E 


\section{Introduction}

Spermatozoa integrity and maturity are important traits for reproductive potential of cockerels [1]. Sperm damage negatively affects the quality of spermatozoa and it may result in poor fertility. High quality spermatozoa rely on normal spermatogenesis. Higher levels of spermatozoa damage are due to spermatozoa susceptibility to damage during a number of stages of spermatogenesis. Spermatozoa damage may take place within the testis, epididymis or ejaculates. The regulation of spermatogenesis is thought to be by means of steroids [2], such as testosterone, and does not proceed normally if the testis is deprived of endocrine support.

The impact of nutrition on sperm quality had been studied [3] and positive correlation between sperm quality and fertility had been reported in several studies [4]. Supplementing diets with polyunsaturated fatty acids was proposed as a strategy for enhancing the production of high quality spermatozoa. The presence of polyunsaturated fatty acids in cellular membranes is important to maintain the soundness of the lipid bilayer [5]. The lipids of the spermatozoa are important for the fluidity and flexibility of spermatozoa [6]. However, high concentrations of polyunsaturated fatty acids in the membrane make the spermatozoa to be highly susceptible to reactive oxygen species that leads to lipid peroxidation.

Spermatozoa are well equipped with an array of antioxidants against reactive oxygen species, but an imbalance between the production of reactive oxygen species and the available defence antioxidants results in oxidative stress [5] [7] [8]. Antioxidants are the main defence against oxidative stress [9]. Vitamin E is the primary component of the antioxidant system of spermatozoa. It is one of the major membrane protectants against reactive oxygen species. Furthermore, selenium is a major dietary microelement required by tissues, which is essential for the maintenance of spermatogenesis and male fertility. It performs its biological functions as the amino acid selenocystein that is incorporated in the primary structure of the component of the selenoprotein family [1]. The role of selenium can be mediated via selenoenzymes such as glutathione. The glutathione peroxides are a family of antioxidants. In chickens, glutathione together with vitamin E prevents lipid peroxidation in spermatozoa [10]. The best characterized spermatozoa effects of selenium deficiency are mid-piece abnormalities [11]. In chickens, selenium reduced the percentage of mid-piece abnormalities and enhanced the antioxidative status of seminal plasma in semen samples [1] [11]. The objective of the study was to determine whether supplementing the cockerel diet with polyunsaturated fatty acids with, or without additional antioxidants (vitamin E and selenium) would improve the spermatozoa quantity and quality.

\section{Materials and Methods}

\subsection{Experimental Animal}

The study was conducted at the Agricultural Research Council, Irene at the Poultry breeding section. Pure-bred Potchefstroom Koekoek chickens from the Irene flock were used. All birds were initially raised in floor pens up to 24 weeks of age. At 24 weeks of age, 60 cockerels were selected from the base population. Thereafter, cockerels were housed in individual cages of $47 \mathrm{~cm} \times 32 \mathrm{~cm} \times 61 \mathrm{~cm}$. The selected chickens were examined for external parasites, particularly poultry lice and treated accordingly. Feathers of cockerels around the vent area were clipped.

At 36 weeks of age, 60 cockerels were randomly allocated into five dietary treatments with 12 cockerels per dietary treatment. The three treatment diets are presented in Table 1 . The two control diets were commercial diets with unknown specifications due to business reasons. The control diets consisted of a commercial layer diet (CL) (negative control); commercial cockerel layer breeder diet (CC) (positive control); modified layer diet (ML), modified layer diet +PUFA (MLP) modified layer diet +PUFA+ antioxidants (MLPA). The dietary treatments were formulated to meet nutrient requirements of the cockerel breeder diet, as established by [12]. Lighting regime was 16 hours light and 8 hour darkness. The experimental and control diets were presented in the form of mash and drinking water was supplied ad libitum by means of nipple drinkers.

At 36 weeks of age, each cockerel was trained for semen collection using the massage technique [13] for 14 days prior commencement of semen collection. Six cockerels that exhibited a positive response to the massage technique and had a $75 \%$ sperm motility were selected from the base population $(n=12)$ of each dietary treatment group. Individual males were considered to be the experimental unit of replication. Semen was collected twice weekly (Tuesdays and Fridays) from each cockerel throughout its reproductive period. During semen collection, the collection tube was maintained at $40^{\circ} \mathrm{C}$ in a thermo flask. 
Table 1. Composition of the experimental diets used in this trial.

\begin{tabular}{cccc}
\hline Composition \% & ML & MLP & MLPA \\
\hline Maize & 69.27 & 69.27 & 69.27 \\
Soyabean full fat & 8.02 & 8.02 & 8.02 \\
Soyabean 44 & 19.73 & 14.73 & 14.73 \\
Fish oil & 0.0 & 5.0 & 5.0 \\
L-lysine & 0.06 & 0.06 & 0.06 \\
DL-methionine $_{\text {Vit-min premix }}{ }^{2}$ & 0.03 & 0.03 & 0.03 \\
Vit-min premix plus & & & 0.15 \\
Vit-min premix plus AO & & & 0.15 \\
Limestone $_{\text {Salt }}$ & & 0.15 & 0.9 \\
Mono Ca phosphate & 0.9 & 0.9 & 0.2 \\
\hline
\end{tabular}

${ }^{\#} \mathrm{LD}=$ layer diet, $\mathrm{CCD}=$ commercial cockerel, $\mathrm{MLD}=$ modified layer diet, modified layer diet+PUFA diet, $\mathrm{ML}+\mathrm{P}+\mathrm{AD}=$ modified layer diet+PUFA+ antioxidants diet; ${ }^{1}$ Vitamin A 10,000,000 IU, vitamin D3 3,000,000 IU, vitamin E 20,000 Mg, vitamin K3 $3000 \mathrm{Mg}$, folic acid $500 \mathrm{Mg}$, niacin 30,000 Mg, D-calpan 10,000 Mg, vitamin B1 $2000 \mathrm{Mg}$, vitamin B2 $5000 \mathrm{Mg}$, vitamin $63000 \mathrm{Mg}$, vitamin $1220 \mathrm{Mg}$, biotin $60 \mathrm{Mg}$, antioxidant $3500 \mathrm{Mg}$, choline $300,000 \mathrm{Mg}$, iron 70,000 Mg, copper $8000 \mathrm{Mg}$, zinc 100,000 Mg, cobalt $500 \mathrm{Mg}$, manganese 120,000 Mg, iodine $1000 \mathrm{Mg}$, selenium $250 \mathrm{Mg}$, ronozyme NP 90,000 Mg; ${ }^{2}$ Vitamin A 10,000,000 IU, vitamin D3 3,000,000 IU, vitamin E 20,000 Mg, vitamin K3 $3000 \mathrm{Mg}$, folic acid $500 \mathrm{Mg}$, niacin 30,000 Mg, D-calpan 10,000 Mg, vitamin B1 $2000 \mathrm{Mg}$, vitamin B2 $5000 \mathrm{Mg}$, vitamin $63000 \mathrm{Mg}$, vitamin $1220 \mathrm{Mg}$, biotin $60 \mathrm{Mg}$, antioxidant $3500 \mathrm{Mg}$, choline 300,000 Mg, iron 70,000 Mg, copper $8000 \mathrm{Mg}$, zinc 100,000 Mg, cobalt $500 \mathrm{Mg}$, manganese 120,000 Mg, iodine 1000 $\mathrm{Mg}$, selenium $250 \mathrm{Mg}$, ronozyme $\mathrm{NP} 90,000 \mathrm{Mg} ;{ }^{3}$ Vitamin A 10,000,000 IU, vitamin D3 3,000,000 IU, vitamin E 200,000 Mg, vitamin K3 $3000 \mathrm{Mg}$, folic acid $500 \mathrm{Mg}$, niacin 30,000 Mg, D-calpan 10,000 Mg, vitamin B1 $2000 \mathrm{Mg}$, vitamin B2 $5000 \mathrm{Mg}$, vitamin $63000 \mathrm{Mg}$, vitamin $1220 \mathrm{Mg}$, biotin $60 \mathrm{Mg}$, antioxidant $3500 \mathrm{Mg}$, choline $300,000 \mathrm{Mg}$, iron 70,000 Mg, copper $8000 \mathrm{Mg}$, zinc 100,000 Mg, cobalt $500 \mathrm{Mg}$, manganese $120,000 \mathrm{Mg}$, iodine $1000 \mathrm{Mg}$, selenium $500 \mathrm{Mg}$, ronozyme NP 90,000 Mg.

\subsection{Semen Volume and Sperm Concentration}

Immediately after semen collection, the volume was determined using a graded-level collection tube. Sperm concentration of the semen samples was determined using a spectrophotometer.

\subsection{Sperm Morphology}

Spermatozoa morphology was examined from smears stained with eosin/nigrosin [14]. The sperm smear was evaluated the same day of semen collection, using slide preparation with the aid of a fluorescent microscope using an oil immersion objective (100× magnification). At each preparation, 200 cells were counted and the percentage of various defects was calculated. The proportion of live (eosin-impermeable) and dead (eosin-permeable) spermatozoa in the sample was assessed on the basis of 200 spermatozoa. The numbers of morphological defects of mid-piece, mid-piece plus droplet, proximal droplet, distal droplet, coiled tailed of spermatozoa proportion were recorded for each sample.

\subsection{Statistical Analysis}

The statistical program GenStat ${ }^{\circledR}[15]$ was used for the analysis of the data. Linear mixed model repeated measurements analysis, also known as REMl analysis [16], was applied to semen values. The means were separated using Fisher's unprotected t-test least significant difference (LSD) and the data were tested at the 5\% level of significance.

\section{Results}

The effects of polyunsaturated fatty acids and antioxidants on semen quality of Potchefstroom Koekoek cockerels are shown in Table 2. The results showed that the semen quality parameters (volume and concentration) were not significantly different between the experimental groups.

A summary of the values for the morphological characteristics of spermatozoa are presented in Table 3 . The 
Table 2. Effects of dietary treatments on semen quantity parameters of cockerels.

\begin{tabular}{cccccccc}
\hline \multirow{2}{*}{ Parameters } & \multicolumn{5}{c}{ Dietary treatments } \\
\cline { 2 - 7 } & $\mathrm{CL}$ & $\mathrm{CC}$ & $\mathrm{ML}$ & MLP & MLPA & p-value \\
\hline Volume $(\mathrm{ml})$ & $0.49 \pm 0.03$ & $0.50 \pm 0.04$ & $0.44 \pm 0.04$ & $0.38 \pm 0.03$ & $0.43 \pm 0.04$ & 0.479 \\
Concentration $\left(\times 10^{9} / \mathrm{ml}\right)$ & $5.2 \pm 317$ & $5.0 \pm 323$ & $5.1 \pm 328$ & $5.1 \pm 315$ & $4.8 \pm 327$ & 0.816 \\
\hline
\end{tabular}

Table 3. Effects of different dietary treatments on sperm morphology parameters of cockerels.

\begin{tabular}{cccccc}
\hline & \multicolumn{3}{c}{ Dietary treatments } \\
Parameters (\%) & CL & CC & ML & MLP & MLPA \\
\cline { 2 - 5 } & $71.5 \pm 0.100^{\mathrm{d}}$ & $76.1 \pm 0.101^{\mathrm{b}}$ & $74.1 \pm 0.101^{\mathrm{c}}$ & $76.4 \pm 0.101^{\mathrm{b}}$ & $82.5 \pm 0.101^{\mathrm{a}}$ \\
Live and normal & $7.75 \pm 0.1$ & $7.26 \pm 0.1$ & $7.36 \pm 0.1$ & $7.37 \pm 0.1$ & $6.72 \pm 0.1$ \\
Dead & $5.83 \pm 0.17^{\mathrm{a}}$ & $4.67 \pm 0.17^{\mathrm{b}}$ & $4.69 \pm 0.17^{\mathrm{b}}$ & $4.04 \pm 0.17^{\mathrm{b}}$ & $2.57 \pm 0.17^{\mathrm{c}}$ \\
Bent mid-piece & $0.45 \pm 0.97^{\mathrm{a}}$ & $0.18 \pm 0.98^{\mathrm{b}}$ & $0.38 \pm 0.97^{\mathrm{a}}$ & $0.20 \pm 0.98^{\mathrm{b}}$ & $0.22 \pm 0.97^{\mathrm{b}}$ \\
Bent mid-piece plus droplets & $2.48 \pm 0.36^{\mathrm{ab}}$ & $2.12 \pm 0.36^{\mathrm{b}}$ & $2.53 \pm 0.36^{\mathrm{a}}$ & $2.56 \pm 0.36^{\mathrm{a}}$ & $0.67 \pm 0.37^{\mathrm{c}}$ \\
Proximal droplets & $3.61 \pm 0.25^{\mathrm{a}}$ & $2.82 \pm 0.25^{\mathrm{b}}$ & $3.21 \pm 0.25^{\mathrm{ab}}$ & $2.85 \pm 0.25^{\mathrm{b}}$ & $1.09 \pm 0.26^{\mathrm{c}}$ \\
Distal droplets & $2.62 \pm 0.22^{\mathrm{a}}$ & $2.78 \pm 0.22^{\mathrm{a}}$ & $1.82 \pm 0.23^{\mathrm{bc}}$ & $1.49 \pm 0.23^{\mathrm{c}}$ & $1.96 \pm 0.23^{\mathrm{b}}$ \\
Coiled tailed & $2.01 \pm 0.11^{\mathrm{b}}$ & $1.57 \pm 0.118^{\mathrm{c}}$ & $2.12 \pm 0.11^{\mathrm{b}}$ & $2.02 \pm 0.11^{\mathrm{ab}}$ & $2.52 \pm 0.11^{\mathrm{a}}$ \\
\hline Abnormal loose head & & &
\end{tabular}

Values are expressed as mean \pm SEM. Rows with different letters are significantly different $(\mathrm{p}<0.05)$.

number of live and normal spermatozoa of the cockerels fed MLPA diet was significantly higher than the other treatments. Cockerels fed CL diet presented the lowest percentage of live and normal spermatozoa. The percentage of dead spermatozoa did not differ significantly between the groups. The percentage of bent mid-piece was significantly lower in the cockerels fed MLPA diet than any other treatment. The percentage of bent mid-piece plus droplets of the cockerels fed CC, MLP and MLPA were lower than in the cockerels fed CL and ML. The percentage of proximal droplets and distal droplets were significantly lower in the cockerels fed MLPA compared to other treatments. The mean percentages of coiled tails were significantly lower on the treatment groups than in the groups on the commercial control diets (CL and CC). The cockerels fed MLPA diet had high percentage of abnormal loose head than the other treatments.

\section{Discussions}

Supplementation of polyunsaturated fatty acids in the cockerel diet did not result in the improvement of semen volume and concentration. Several studies have shown that supplementation of dietary lipids in the diet does not alter the semen volume and semen concentration [5] [8]. The results of this study were in line with that of [6] who found similar results when feeding cockerels with diets supplemented with different polyunsaturated fatty acids.

Results of the present study indicated a significant increase in the occurrence of live and normal spermatozoa in the cockerels fed the MLPA diet compared with other groups. Earlier studies showed that mature spermatozoa were enriched with polyunsaturated fatty acids in which the effects of oxidative stress were inevitable. Vitamin $\mathrm{E}$ is located in the spermatozoa where it performs its antioxidant role [17]. Therefore, the antioxidant role of vitamin $E$ in protecting the sperm plasma membrane seems to come from within the spermatozoa, since its origin of concentration is in the membrane not in the seminal plasma. The increased number of spermatozoa with intact membranes induced by vitamin $\mathrm{E}$ has been shown to increase live and normal spermatozoa [9]. The high percentage of live and normal spermatozoa shows that vitamin $\mathrm{E}$ is capable of improving the sperm quality which is in agreement with the results of [4].

Selenium is also an essential trace element that plays an important role in a number of physiological processes including avian reproduction [10]. This element becomes crucial in maintaining spermatogenesis and in limiting 
or preventing mid-piece abnormalities [18]. In the present study, a significant decrease in the bend mid-piece abnormalities was found in the cockerels fed the MLPA diet supplemented with antioxidants compared with the other groups. This was in agreement with the observations by [1] that showed decreased mid-piece abnormalities in cockerels fed a diet supplemented with selenium.

All the spermatozoa possess proximal droplets during the transit in the caput epididymis. It was reported that when spermatozoa underwent final maturational changes, proximal droplets migrated to the annular region (distal droplets) during transit in the cauda epididymis [19]. Sometimes the cytoplasmic droplets are retained in the proximal region and can be identified in the ejaculates [20]. Such a defect would explain the relationship with poor morphology. Selenium becomes crucial in maintaining spermatogenesis. In the present study, the cockerels fed the MLPA diet had a decreased incidence of proximal droplets compared with other groups. The reduction of proximal droplets in the ejaculates can be explained by the supplementation of antioxidants in the cockerels fed the MLPA diet.

In order to produce normal spermatozoa, distal droplets are shed when spermatozoa are exposed to seminal plasma during ejaculation [19]. The presence of high percentage of distal cytoplasmic droplets in the semen is considered to be a sign of disturbance in spermiogenesis [21]. Selenium is an essential trace element that plays an important role in normal spermatogenesis [21]. Apart from having normal spermatogenesis [10] [21], it is important for an antioxidant effect [1]. Therefore, selenium is responsible for some of the mature spermatozoa showing low levels of distal cytoplasmic retention in the cockerels fed MLPA diet.

Zinc is concentrated in the tail region of the sperm [22]. It is crucial in membrane stability and for mechanical properties of tail morphology [1] [4] [23] show that zinc is involved in the control of sperm motility through its association with ATP in contraction and its regulation of phospholipid energy reserves. In the present study, the treatment groups were supplemented with higher zinc levels compared with the control groups, which consequently had higher percentages of coiled tails. Therefore, the decrease in the percentage of coiled tails in the treatment groups may be due to the supplementation of zinc. Zinc supplementation was proved effective in reduction of coiled tailed abnormalities in the treatment groups. In conclusion, this study shows that supplementation of polyunsaturated fatty acids and antioxidants may be complementary to each other in improving the morphological quality of spermatozoa. However, further studies are recommended to confirm these results and explore other polyunsaturated fatty acids, antioxidants and trace minerals.

\section{Acknowledgements}

The authors are grateful to the Poultry Breeding Section and their technical assistants for their help.

\section{References}

[1] Satiago-Moreno, J., Castano, C., Coloma, M.A., Gomez-Brunet, A., Toledano-Diaz, A., Lopez-Sebastian, A. and Campo, J.L. (2009) Use of the Hypo-Osmotic Swelling Test and Aniline Blue Staining to Improve the Evaluation of Seasonal Sperm Variation in Native Spanish Free-Range Poultry. Poultry Science, 88, 2661-2669. http://dx.doi.org/10.3382/ps.2008-00542

[2] Martin, G.B. and Hotzel, M.J. (1992) The Effects of Nutrition on Reproductive Endocrinology. Proceedings of the Nutrition Society of Australia, 17, 177-185.

[3] Bilcik, B., Estevez, I. and Russek-Cohen, E. (2005) Reproductive Success of Broiler Breeders in Natural Mating Systems: The Effect of Male-Male Competition, Sperm Quality, and Morphological Characteristics. Poultry Science, 84, 1453-1462. http://dx.doi.org/10.1093/ps/84.9.1453

[4] Barber, S.J., Parker, H.M. and Mcdaniel, C.D. (2005) Broiler Breeder Semen Quality as Affected by Trace Minerals in Vitro. Poultry Science, 84, 100-105. http://dx.doi.org/10.1093/ps/84.1.100

[5] Kelso, K.A., Cerolini, S., Noble, R.C., Sparks, N.H.C. and Speake, B.K. (1996) Lipid and Antioxidant Changes in Semen of Broiler Fowl from 25 to 60 Weeks of Age. Journal of Reproduction and Fertility, 106, 201-206. http://dx.doi.org/10.1530/jrf.0.1060201

[6] Edens, F.W. and Sefton, A.E. (2009) Sel-Pex ${ }^{\circledR}$ Improves Spermatozoa Morphology in Broiler Males. International Journal of Poultry Science, 8, 853-861. http://dx.doi.org/10.3923/ijps.2009.853.861

[7] Golzar-Adabi, S.H., Cooper, R.G., Kamali, M.A. and Hajbabaei, A. (2011) The Influence of Inclusions of Vitamin E and Corn Oil on Semen Traits of Japanese Quail (Coturnix coturnix japonica). Animal Reproduction Science, 123, 119-125. http://dx.doi.org/10.1016/j.anireprosci.2010.11.006

[8] Surai, P.F., Noble, R.C., Sparks, N.H.C. and Speake, B.K. (2000) Effect of Long-Term Supplementation with Arachi- 
donic or Docosahexaenoic Acids on Sperm Production in the Broiler Chicken. Journal of Reproduction and Fertility, 120, 257-264.

[9] National Research Council (1994) Nutrients Requirements of Domestic Animals. Nutrient Requirements of Poultry. 9th Edition, National Academic Press, Washington DC.

[10] Surai, P.F., Kostjuk, I., Wishart, G.C., Macpherson, A., Speake, B.K. Noble, R.C. Ionov, I. and Kutz, E. (1998) Effect of Vitamin E and Selenium Supplementation of Cockerel Diets on Glutathione Peroxidase Activity and Lipid Peroxidation Susceptibility in Sperm, Testes and Liver. Biological Trace Element Research, 64, 6401-6403. http://dx.doi.org/10.1007/BF02783329

[11] Al-Daraji, H.J., Al-Mashsdani, H.A., Al-Hayani, W.K., Al-Hassani, A.S. and Mirza, H.A. (2010) Effect of n-3 and n-6 Fatty Acids Supplemented Diets on Semen Quality in Japanese Quail (Coturnix coturnix japonica). International Journal of Poultry Science, 9, 656-663. http://dx.doi.org/10.3923/ijps.2010.656.663

[12] Burrows, W.H. and Quinn, J.P. (1937) The Collection of Spermatozoa from Domestic Fowl and Turkey. Poultry Science, 14, 251-254. http://dx.doi.org/10.3382/ps.0140251

[13] Blesbois, E., Douard, V., Germain, M., Boniface, P. and Pellet, F. (2004) Effects of n-3 Polyunsaturated Dietary Supplementation on the Reproductive Capacity of Male Turkeys. Theriogenology, 61, 537-549. http://dx.doi.org/10.1016/S0093-691X(03)00207-3

[14] Tabatabaei, S., Batavani, R.V. and Talebi, A.R. (2009) Comparison of Semen Quality in Indigenous and Ross Broiler Breeder Roosters. Journal of Animal and Veterinary Advances, 8, 90-93.

[15] Payne, R.W., Welham, S.J. and Harding, S.A. (2012) A Guide to REML in Genstat ${ }^{\circledR}$ for Windows ${ }^{\mathrm{TM}}$. 15th Edition, VSN International, Oxford.

[16] Payne, R.W., Murray, D.A., Harding, S.A., Baird, D.B. and Soutar, D.M. (2012) Genstat ${ }^{\circledR}$ for Windows ${ }^{\text {TM }}$. 15th Edition, Introduction, VSN International, Oxford.

[17] Bongalhardo, D.C., Leeson, S. and Buhr, M.M. (2009) Dietary Lipids Differently Affect Membranes from Different Areas of Rooster Sperm. Poultry Science, 88, 1060-1069. http://dx.doi.org/10.3382/ps.2008-00392

[18] Zhang, H., Lu, S., Ma, Y.M., Li, X. and Chen, Z. (2008) Early Apoptotic Changes in Human Spermatozoa and Their Relationships with Conventional Semen Parameters and Sperm DNA Fragmentation. Asian Journal of Andrology, 10, 227-235. http://dx.doi.org/10.1111/j.1745-7262.2008.00295.x

[19] Biwas, A., Mohan, J. and Sastry, K.V.H. (2009) Effects of Higher Dietary Vitamin E Concentrations on Physical and Biochemical Characteristics of Semen in Kadaknath Cockerels. British Poultry Science, 50, 733-738. http://dx.doi.org/10.1080/00071660903264369

[20] Sakkas, D., Moffat, O., Manicardi, G.C., Mariethoz, E., Tarozzi, N. and Bizzaro, D. (2002) Nature of DNA Damage in Ejaculated Human Spermatozoa and the Possible Involvement of Apoptosis. Biology Reproduction, 66, 1061-1067. http://dx.doi.org/10.1095/biolreprod66.4.1061

[21] Mogielnicka-Brzozowska, M., Wysocki, P., Strzezek, J. and Kordan, W. (2011) Zinc-Binding Proteins from Boar Seminal Plasma Isolation, Biochemical Characteristics and Influence on Spermatozoa Stored at $4^{\circ}$ C. Acta Biochimica Polonica, 58, 171-177.

[22] Jerysz, A. and Lukaszewicz, E. (2013) Effect of Dietary Selenium and Vitamin E on Genders' Response to Semen Collection and Ejaculate Characteristics. Biological Trace Element Research, 153, 196-204. http://dx.doi.org/10.1007/s12011-013-9652-5

[23] Mahmood, H.M.A. and Al-Daraji, H.Z. (2011) Effect of Dietary Supplementation with Different Level of Zinc on Sperm Egg Penetration and Fertility Traits of Broiler Breeder Chicken. Pakistan Journal of Nutrition, 10, 1083-1088. http://dx.doi.org/10.3923/pjn.2011.1083.1088 